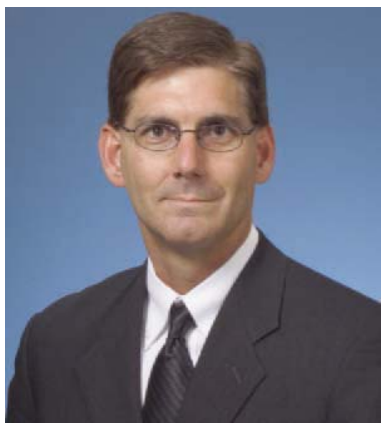

\section{Reflections and Resolutions}

This is the time of year where we usually reflect on the year that just passed and we make plans and resolutions for the year that we are about to begin. The year 2010 was a particularly hard year for me with the loss of my girlfriend, Jill, to cancer. The one thing worth remembering that I would like to share with you from 2010 is something that she taught me and would mention to me frequently: "Do not waste your day!" Before this, I had contemplated wasting a year or a month, but not whether I had really made my day count. What she meant was that whether you have had a good day or a bad day is completely up to you, and it starts with your morning attitude. Did you do something fun, worthwhile, or achieve something hard? Did you help someone? This concept also couples to the fact that you can decide in the morning whether you are going to have a positive impact or a negative impact on people's lives within your day. This concept works well, and I can now practice this concept most days (in the positive direction).

I also reflect every year by watching Jimmy Valvano's 1993 ESPY speech on YouTube. He also lost his life battling cancer, and his guiding life goals were ( $I$ ) to laugh, (ii) to think, and (iii) to cry (tears of joy, sorrow, or passion) every day. Above all, if you are not passionate about what you do, leave today and go find something that you are passionate about. Life is too short not to do this. These are themes that propagate through many teachings and observations when a life ends early and important life lessons become crystal clear. Randy Pausch's "Last Lecture" also teaches these same themes.

On a lighter note, I am passionate about being an optical engineer and also passionate about being editor-in-chief of Optical Engineering! For 2010 reflections, we started with a few special sections in Optical Engineering and the results were good. We recruited a number of tutorials and review papers on topics that are interesting and relevant. Most of these will be 2011 papers. We created a student advisory board that has given us really good insight into the desires of younger researchers related to publication. I also spent time with quite a few universities and laboratories giving talks on optical engineering. Finally, we continued to decline what Don O'Shea called "not wrong" papers (I call them "so what?" papers), where the significance is just not present in the paper. These submitted papers are the result of enormous pressure from the science and engineering leadership in many countries to publish in refereed journals for career advancement opportunities and recognition.

As for 2011 resolutions, we will have a big year in terms of special sections. The scheduled special sections are, again,all interesting and relevant, and include some exciting topics. We will continue to comb through the hot topics at conferences to find areas with the highest interest and relevance for our community and make our journal as useful to our members and readers as possible. I will continue to monitor the top SPIE Proceedings downloaded each quarter and ensure that these papers are encouraged to submit a more polished version to the journal. The SPIE publication community (leadership, staff, and board) has a number of exciting initiatives to help us determine the most interesting and relevant content associated with conferences and other activities, and they make it straightforward to convert this information into proceedings and journal papers. Many of these efforts are being pursued by the SPIE Digital Library. My primary resolution this year is to improve the service of Optical Engineering to the science and engineering community through measureable quantities, such as impact factor, downloads, time to publication, and subscriptions.

On resolutions, I used to be a "list" person. I had to write down a few resolutions each year for family, religion, finances, career, personal development, and health. I always put down a few things that were fun. Even though l've not made a list in the past few years, I probably will this year. On reflections, James Taylor has a song with a verse in it that says: "the secret of life is enjoying the passing of time." This song always reminds me that life is more about the journey than the destination. I have never been satisfied with a destination, but have frequently been very happy with the road ahead even though it was unknown (because you have the power to shape it). I truly enjoyed my time with Jill and will continue to practice making my days count.

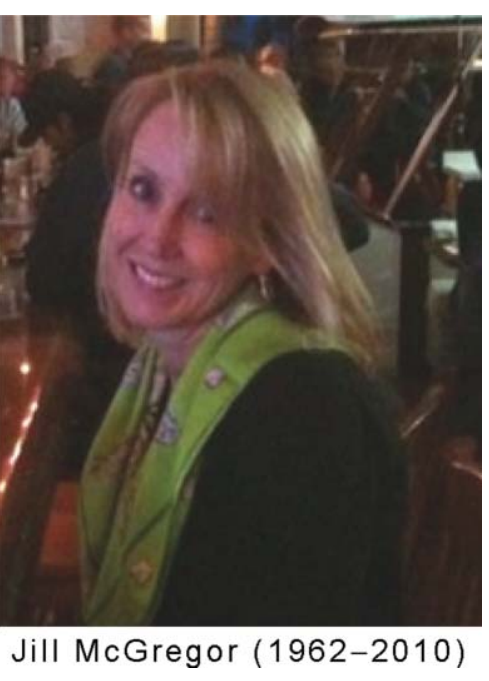

Ronald G. Driggers Editor 